\title{
A model of orthotopic murine bladder (MBT-2) tumor implants
}

\begin{abstract}
We produced a model of orthotopic transplantation in $\mathrm{C} 3 \mathrm{H} / \mathrm{He}$ mice by transplanting MBT-2 cells. A single-cell suspension of $1.0 \times 10^{5} \mathrm{MBT}-2$ cells/ $0.02 \mathrm{ml}$ was successfully injected into the submucosal layer of the bladder, with an incidence of $100 \%$ after four experimental weeks. Inoculated tumor grew expansively into the bladder cavity from the bladder submucosa and invaded the serosa and the surrounding tissue. This model more closely resembled the characteristics of human bladder tumor when compared to other bladder cancer models. The results of the histological observation, electron microscopic examination and DNA content analysis by flow cytometry showed that the transplanted carcinoma maintained the biologic characteristics of the primary tumor.
\end{abstract}

Key words Bladder tumor $\cdot$ Mouse $\cdot$ Orthotopic transplantation

\section{Introduction}

The orthotopic murine bladder tumor is an invaluable experimental tool for assessing potential therapeutic agents against bladder carcinoma. It has been used for evaluating intravesical therapy [bacillus calmette guérin (BCG) and interleukin-2 (IL-2) [1, 2, 7]. Soloway [9] has successfully established a localized transitional cell carcinoma model in mice using intravesical instillation of tumor cell suspension (MBT-2) into denuded [by $N$-methyl- $N$-nitrosourea (MNU)] focally fulgurated bladder [9]. However, this method can only be applied

F. Jiang $(\bowtie)$

Institute of Pathology, University of Basel,

Schönbeinstrasse 40, CH-4003 Basel, Switzerland

X.-M. Zhou

Department of Urology, Nanjing Railway Medical College,

Nanjing 210009, People's Republic of China to female mice and often produces urinary stones. The success rate of the tumor implantation method varies between $50 \%$ and $70 \%[9,10]$. A study was undertaken to investigate the possibility of developing a orthotopic tumor model in mice by injecting tumor cell suspension into the submucosal layer of the bladders of syngenic animals.

\section{Materials and methods}

Tumor cells and tumor implantation

N-(4-(5-Nitro-2-furgl)-2-thiazolyl) formamide (FANFT)-induced MBT-2 transitional cell carcinoma of the bladder (originally derived by Dr. Soloway) was maintained in vivo as a solid subcutaneous growing tumor by serial transplantation in syngenic $\mathrm{C}_{3} \mathrm{H} / \mathrm{He}$ mice (Charles River), and in vitro in RPMI1640 medium plus $10 \%$ fetal calf serum. Single tumor suspension was prepared by mincing the tumor under sterile conditions and adding to the minced tissue $5 \mathrm{ml}$ of an enzyme cocktail containing a mixture of $1 \%$ collagenase (Sigma, type II), $0.01 \%$ proteinase K (Sigma) and $0.01 \%$ DNAase (Sigma) in Dulbecco's phosphate-buffered saline (PBS). The cells were than washed twice with RPMI1640 medium, resuspended to the required concentration. The viability was always more than $90 \%$ by the trypan blue exclusion method. The final concentration of the suspension was adjusted to $5.0 \times 10^{7}, 1.0 \times 10^{5}$ and $1.0 \times 10^{3}$ cells in $0.02 \mathrm{ml}$ by dilution with the 1640 medium. The operation was performed with the mice under general anesthesia from a single dose of intraperitoneal sodium phenobarbital $(130 \mathrm{mg} / \mathrm{kg}$ body weight). The urinary bladder was exposed through a low midline incision, the bladder was explored for tumor, $0.02 \mathrm{ml}$ tumor suspension was injected into the submucosal layer of the bladders so as to make a "semitransparent bubble" for the submucosal layer tumor model, then omentum was drawn over the operation area. The procedure took place under clean but not sterile conditions and was performed without a magnifying glass. Animals were placed on antibiotics (tetracycline, $250 \mathrm{mg} / 500 \mathrm{ml}$ drinking water) for 5 days after the operation.

\section{Experimental groups}

An intermediate dosis of tumor cells $\left(1.0 \times 10^{5}\right.$ viable cells in $0.02 \mathrm{ml}$ ) was injected into 48 mice. These mice were randomized into six groups $(n=8$ each). The animals were inspected for: (a) weight loss, (b) the time of the appearance of the tumor and (c) palpation of the suprapubic mass. Mice of groups 1-5 were 
sacrificed at 1,2, 3, 4 and 5 weeks post-tumor implant, respectively. The sixth group was used as a group for observation of the survival time of the tumor-bearing animals. The large dose of tumor cells $\left(5.0 \times 10^{7}\right.$ cells in $\left.0.02 \mathrm{ml}\right)$ and the small dose of tumor cells $\left(1.0 \times 10^{3}\right.$ cells in $\left.0.02 \mathrm{ml}\right)$ was injected into 20 mice each in order to demonstrate the relationship between the time of the appearance and the number of the injected cells. An additional ten normal mice injected with $0.02 \mathrm{ml}$ RPMI1640 medium were used as normal control group. For pathological and histological examination, cystectomy was performed via a midline incision after the bladder was distended with $0.1 \mathrm{ml}$ formalin and the urethra ligated at the bladder neck. Tumor incidence and tumor weight were determined. Tumor weight was expected to be similar to the weight of a neoplastic bladder. Histological examination was performed with hematoxylin and eosin (H\&E) staining on fixed whole bladder sections from the cystectomy specimens. The bladders were carefully inspected for: (a) tumor incidence and (b) histological grade. Other organs were examined for gross abnormalities, and the kidneys, lungs, liver, uterus, spleen and pancreas were routinely processed for histology.

A fragment of the grade II tumors from group 5 was fixed in $3 \%$ glutaraldehyde and then postfixed in $\mathrm{OsO}_{4}$, dehydrated in graded alcohol and embedded in Epon 812 (Carl Roth, Karlsruhe). Ultrathin sections were prepared with diamond knives, stained with uranyl acetate and lead citrate, and viewed with an H-600 electron microscope. A $4 \times 4-\mathrm{mm}$ piece of the grade II bladder tumor from group 5 was minced and stored frozen at $-80^{\circ} \mathrm{C}$ in a solution of $5 \%$ dimethylsulfoxide, $250 \mathrm{~mm}$ sucrose and $40 \mathrm{~mm}$ trisodium citrate until analysis. The tissue was minced into pieces approximately $1 \mathrm{~mm}$ in diameter and subsequently enzymatically dissociated using collagenase type $(200 \mathrm{U} / \mathrm{ml})$ and DNAse $(500 \mathrm{~K}$ units $\mathrm{U} / \mathrm{ml})$ at $37^{\circ} \mathrm{C}$. DNA histogram display and analysis was performed on a Terak 8600 minicomputer (Terak, Scottsdale, AZ). Full bright fluorescent microspheres (Lot 5325, Coulter Electronics) were used to aid instrument alignment, and as an external fluorescence standard. Murine peripheral blood mononuclear cells were used as an internal reference standard for DNA ploidy analysis. The cells were aliquoted, frozen as above and stained in parallel with the urinary bladder specimens in each flow cytometry run. An aneuploid population was considered present only if unequivocal $G_{0} / G_{1}$ populations were evident.

\section{Results}

\section{General}

The mice that received the middle cell doses all had palpable pubic mass-like soybean at 3 weeks, and half of them had gross hematuria and were fatigued at 3-4 weeks. At 5 weeks, all of them appeared moribund and mean weights of the mice were $13.8 \pm 1.8 \mathrm{~g}$, whereas mice of the control group had a mean weight of

Table 1 Reduction of tumor growth with implantation of $1.0 \times 10^{5}$ tumor cells

\begin{tabular}{llllll}
\hline Groups & $\begin{array}{l}\text { No. of } \\
\text { mice }\end{array}$ & $\begin{array}{l}\text { No. of } \\
\text { dead } \\
\text { mice }\end{array}$ & $\begin{array}{l}\text { Tumor } \\
\text { incidence } \\
(\%)\end{array}$ & $\begin{array}{l}\text { Mean } \\
\text { bladder } \\
\text { weight }(\mathrm{g})\end{array}$ & $\begin{array}{l}\text { Mean } \\
\text { mouse } \\
\text { weight }(\mathrm{g})\end{array}$ \\
\hline 1 & 8 & 0 & 0.0 & $19.5 \pm 4.3$ & $17.9 \pm 1.6$ \\
2 & 8 & 0 & 75.0 & $22.4 \pm 20.5$ & $17.5 \pm 2.0$ \\
3 & 8 & 0 & 88.0 & $350.0 \pm 20.7$ & $15.7 \pm 2.4$ \\
4 & 8 & 0 & 100.0 & $483.5 \pm 44.5$ & $15.4 \pm 3.0$ \\
5 & 8 & 1 & 100.0 & $510.4 \pm 38.5$ & $13.8 \pm 1.8$ \\
6 & 8 & 8 & 100.0 & $540.7 \pm 40.4$ & $12.4 \pm 1.5$ \\
Control & 10 & 0 & 0.0 & $20.0 \pm 4.7$ & $20.2 \pm 1.5$ \\
\hline
\end{tabular}

Table 2 Effect of different numbers of the cells on the growth of the tumor

\begin{tabular}{llll}
\hline & $\begin{array}{l}\text { Time to } \\
\text { appearance } \\
\text { of tumor (weeks) }\end{array}$ & $\begin{array}{l}\text { Tumor } \\
\text { incidence }\end{array}$ & $\begin{array}{l}\text { Mean survival } \\
\text { time (days) }\end{array}$ \\
\hline $1.0 \times 10^{3}$ & 4 & $60.0 \%$ & 58 \\
$1.0 \times 10^{5}$ & 3 & $88.0 \%$ & 52 \\
$1.0 \times 10^{7}$ & 2 & $100.0 \%$ & 26 \\
\hline
\end{tabular}

$20.2 \pm 1.5 \mathrm{~g}$; mean bladder weight of the mice was $510.4 \pm 38.5 \mathrm{mg}$, whereas that of the control group was $20.0 \pm 4.7 \mathrm{mg}$. At 6 weeks post-tumor implant, all mice died (Table 1). There was a good correlation between the tumor incidence and the number of cells at 3 weeks. The mice injected with a small dose of MBT-2 cells had hematuria at 4 weeks and the incidence of the tumor was $60 \%$; they survived 8 weeks after the operation. The mice injected with a large dose of cells had gross hematuria as early as 2 weeks after the procedure and all died at 4 weeks (Table 2).

\section{Pathological changes}

One week after the transplantation, many vital tumor cells were found in the submucosa of the bladder. At 2 weeks, the tumors were grossly visible, their surface appearing papillary or nodular. The color of the cut sections of these tumors was grayish (Fig. 1). After the 3rd week, all tumors found in the bladders were large, occupying more than $50 \%$ of the bladder cross-sectional area. The tumors had hemorrhage or necrosis, and extended into the perivesical fat or surrounding regional areas such as lymph nodes, mesenterium and reproductive organs. At autopsy examination bilateral hydro-
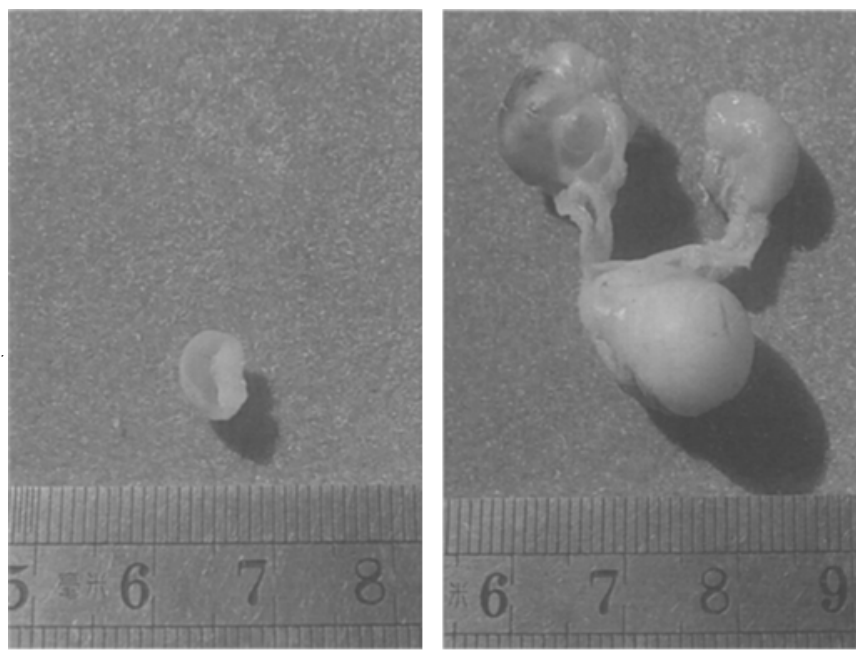

Fig. 1 The bladder partially filled with tumor at 2 weeks post-tumor implant; the color of the cross-section of tumor was grayish white

Fig. 2 Bilateral hydronephrosis was observed with dead mouse at 5 weeks post-tumor implant 


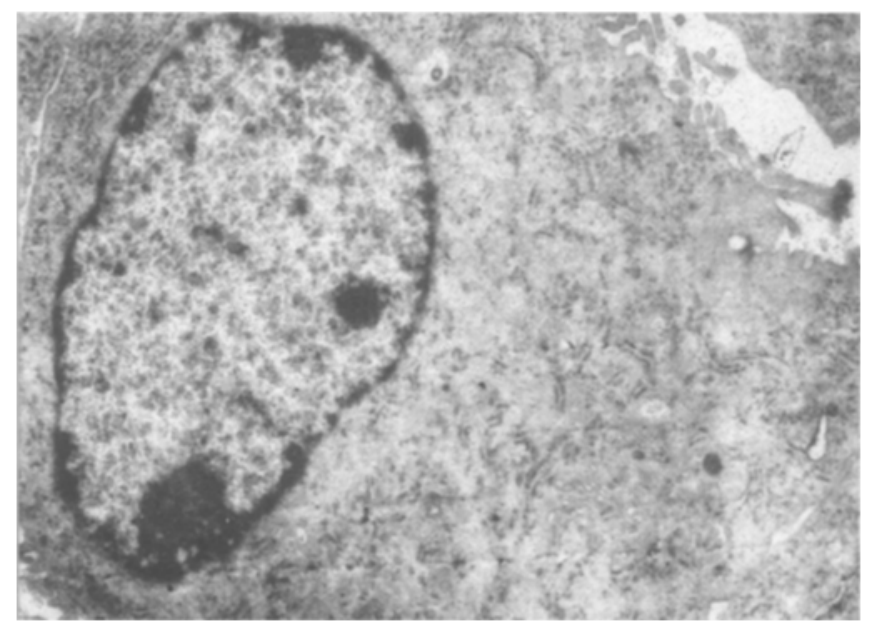

Fig. 3 There was no specialization of the luminal membrane, and no zonula occludes or macula adhaerens. TEM, $\times 6000$

nephrosis was frequently observed (Fig. 2), uremia being the main cause of death. No hematogenous dissemination, particularly to the liver or lungs, was found. Histological examination of the tumor specimens revealed tumor cells characteristic of a poorly differentiated transitional cell carcinoma of the bladder, which demonstrated greater variability in both nuclear size and shape. The transplanted tumors were histologically identical to the original MBT-2 tumors.

\section{Electron microscopy}

The transplanted tumors showed a comparatively clear cytoplasm. Mitochondria were abundant and spherical, and showed vestigial cristae. Both rough- and smoothsurfaced endoplasmic reticulum was seen in quite long stretches. The Golgi apparatus was well developed, with large, open lamellae. The nuclei were round, containing prominent nucleoli. The nuclear membrane was not reentrant, and there was no margination of chromatin. Throughout the tumor, boundaries between cells did not show the complex folding seen in the well-differentiated tumors and the normal epithelium. The tight junctions were poorly formed. The lamina densa of the basement membrane was markedly thickened and multilayered (Fig. 3).

\section{Flow cytometry}

The DNA index (DI) of MBT-2 cells and the transplanted tumor cells was 1.98 and 1.96, respectively, which meant that tumors were tetraploid, and that DNA histograms from these primary tumors and transplanted tumors were identical.

\section{Discussion}

The techniques of inducing urothelial tumor by oral carcinogens such as FANFT or by intravesical instilla- tion of carcinogens such as MNU in rats have been well established. However, these useful models have some shortcomings. They usually require a long period for the tumor to develop: 10-45 weeks for the FANFT model and 12-20 weeks for the MNU model [3, 4]. Furthermore, the entire urothelium of the induced bladder is either hyperplastic or neoplastic, and therefore studies comparing the induced tumor with the surrounding normal mucosa as well as the mechanisms of tumor growth and spreading cannot be performed in these models. Nude mice have been used for many years for heterotransplantation of human tumors. However, studies concerning experimental metastases of human tumors using these experimental animals have been limited because metastases seldom develop in nude mice when they are grafted with human tumor cells. The experimental conditions required for nude mice are very strict. It has been reported that only $29 \%$ of tumor cell lines tested could be successfully used following subcutaneous inoculation in such mice and that metastases of transplanted tumors are not usually observed by gross and microscopic observation; the average survival time of the tumor-bearing animals is usually less than 2 weeks [8]. Previously we described another model for focal bladder carcinoma in rats that had a similar success rate to the present study [5]. However, a disadvantage of our previous model was a high incidence of calculi due to the use of sutures, which may have provided a nucleus for the formation of urinary stones. The operation was very complicated, and our experiments of grafting bladder tumor tissue to bladder of syngenic animals were consistent with the results of previous studies [6]; our results were reported in a previously published study [5]. Moreover, this method has other complications including graft necrosis, with extravasation of urine, graft atrophy and perivesical abscess formation. It is very easy to observe the appearance of the tumor in the murine flank, but the model does not reflect the characteristics of the bladder tumor as an orthotopic tumor model. Furthermore treatment of orthotopic tumors would seem to be a better method since it takes into consideration the concentration of antitumor agent in the urine. Orthotopic models may be used for evaluation of intravesical therapy as well as for systemic therapeutic experiments. It is very important, for intravesical therapy is the best way to decrease a high recurrence rate of bladder cancer. Obviously mice bearing the same tumor in the flank are not used for this kind of test.

Our established model of orthotopic transplantation in mice using MBT-2 has the following characteristics: (a) the incidence of injection and subsequent growth of the transitional tumor cell is $100 \%$ in all groups; (b) the tumors were found in all bladders as early as 2 weeks following tumor implantation into the bladders. The time for the tumor development and survival time of the animals might be controlled by adjusting the dose of the tumor cells implanted. There was a good number-related response of the urinary bladder to the MBT-2 cells injected into the submucosa. It is easy and economical to 
do the operation. (d) The present study utilized a murine transitional cell tumor which closely resembled its human counterpart histologically. Early stage orthotopic murine bladder tumors produced by an identical number of cells were always localized, allowing a comparison of the induced tumor with surrounding normal mucosa as well as the study of the mechanisms of tumor growth and spreading. In addition it is possible to produce and to study multifocal tumors using the described technique. e) The incidence and depth of the tumor correlated very well with the time and dose of tumor cells implanted. Seven days following the procedure, histologic examination of the bladder showed that almost all the cells were in the submucosa but not in the muscular layer. Subsequently, the results of our repetitive experiments demonstrated this phenomenon, which is due to the anatomical characteristics of the murine bladder wall. The submucosal layer is much looser than the muscular layer. It is very easy to inject the cells into the submucosal layer when the bladder is almost empty. The earliest change was simple or orderly hyperplasia followed by nodular and/or papillary and finally invasive carcinomas associated with the area of hemorrhage or necrosis. The sex of mice does not affect the transplantation of tumors since cells were not placed transuretherally into the bladder. (g) Some complications such as retrograde infection and bladder stone might be eliminated effectively because the technique did not involve the bladder cavity.

There are several technical points which are critical to the success of the transplantation. First, it is important that the viability is always more than $90 \%$ using the trypan blue exclusion method. Second, the bladder wall should not be perforated in order to avoid injecting the tumor cells into the cavity. Third, postoperative pro- phylactic antibiotics are essential in preventing infection and maintaining the tumor cells.

We believe that the potential applications of this model are numerous. In addition to being of use for evaluation of chemotherapeutic agents, regimens, and other modalities of treatment of TCC, the model can also be used for the study of basic mechanisms of tumor growth and the spreading and extrinsic and intrinsic factors affecting these processes.

\section{References}

1. Chin J, Kadhim S, Garcia B, Kim Y, Karlik S (1991) Magnetic resonance imaging for detecting and treatment monitoring of orthotopic murine bladder tumor implants. J Urol 145:1297

2. Connor J, Bannerji R, Satio S, Heston W, Fair W, Gilboa E (1993) Regression of bladder tumors in mice treated with IL-2 gene-modified tumor cells. J Exp Med 177:1127

3. Erturk E, Cohen S (1969) Pathogenesis, histology and transplantability of urinary bladder carcinomas induced in albino rats by oral administration of FANFT. Cancer Res 29:2219

4. Hicks RM, Wakefield J St (1993) Rapid induction of bladder cancer in rats with MNU. Chen Biol Interact 5:139:172

5. Jiang F, Zhou X-M (1993) Murine bladder cancer isograft model for focal carcinoma. Chinese J Exp Surg 10:151

6. Okajima E, Ozono S (1991) Experimental bladder tumor. Nippon-Hingokika-Gakkai-Zasshi 82:705

7. Recker F, Otto T (1991) Animal experiment aspects of bladder cancer. Urologe A 30:172

8. Shibayama T, Tachibana M, Deguchi N, Jitsukaws S, Tazaki H (1991) SCIO mice: a suitable model for experimental studies of urologic malignancies. J Urol 146:1136

9. Soloway M (1977) Intravesical and systemic chemotherapy of murine bladder cancer. Cancer Res 37:2918:1977

10. Soloway M, Masters S (1979) Implantation of transitional tumor cells on the cauterized murine urothelial surface. Proc Amer Ass Cancer Res 20:256 